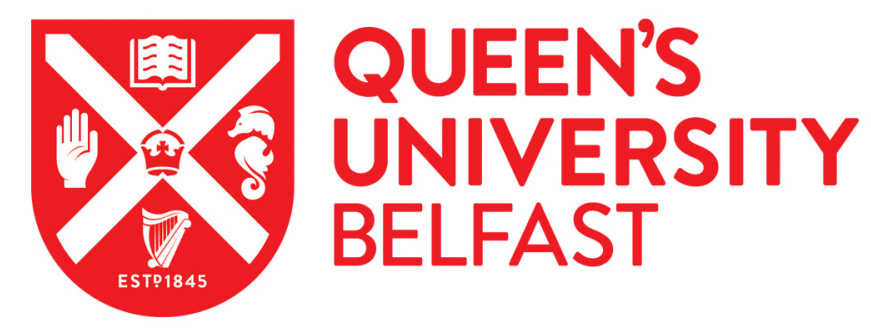

\title{
Does Naturalism Make Room for Teleology? The Case of Donald Crosby and Thomas Nagel
}

Leidenhag, M. (2019). Does Naturalism Make Room for Teleology? The Case of Donald Crosby and Thomas Nagel. American Journal of Theology and Philosophy, 40(1), 5.

Published in:

American Journal of Theology and Philosophy

Document Version:

Peer reviewed version

Queen's University Belfast - Research Portal:

Link to publication record in Queen's University Belfast Research Portal

Publisher rights

Copyright 2019 University of Illinois Press. This work is made available online in accordance with the publisher's policies. Please refer to any applicable terms of use of the publisher.

\section{General rights}

Copyright for the publications made accessible via the Queen's University Belfast Research Portal is retained by the author(s) and / or other copyright owners and it is a condition of accessing these publications that users recognise and abide by the legal requirements associated with these rights.

Take down policy

The Research Portal is Queen's institutional repository that provides access to Queen's research output. Every effort has been made to ensure that content in the Research Portal does not infringe any person's rights, or applicable UK laws. If you discover content in the Research Portal that you believe breaches copyright or violates any law, please contact openaccess@qub.ac.uk. 


\section{DOES NATURALISM MAKE ROOM FOR TELEOLOGY? THE CASE OF DONALD CROSBY AND THOMAS NAGEL}

\section{Mikael Leidenhag / University of Edinburgh}

This article explores an important metaphysical issue raised by Donald Crosby in his Nature as Sacred Ground. ${ }^{1}$ Namely, the reality and nature of teleology and the explanatory relevance of teleology for understanding human mentality. Crosby, in his endeavor to construct a metaphysical system on which to base religious naturalism, acknowledges the importance of positively accounting for teleology. Teleology is crucial for accounting for human freedom, and if teleology falls prey to reductionism (or some version of anti-realism) then a dangerous dissonance is created between naturalism and the necessary presupposition regarding ourselves as experiencing and causally effective creatures. To leave such a dissonance unaddressed would subsequently undermine the metaphysical plausibility and coherency of religious naturalism.

What, then, is the place of teleology within the broader framework of naturalism? Crosby's metaphysical enterprise is based on an emergentist and pluralistic ontology. This ontology is also labeled as "radical materialism". ${ }^{2}$ Materialism is usually equated with determinism and, therefore, rejected in virtue of this association. Crosby, however, maintains that radical materialism is "entirely consistent with a probabilistic rather than determinist vision of the universe, with genuine consciousness and freedom, and with a robust affirmation of the fundamental importance of moral and spiritual realities and values."3 On this picture, materialism does not exclude novelty but provides the ontological basis and necessary physical ingredients for the emergence of new phenomena. Teleology, therefore, is

\footnotetext{
${ }^{1}$ Donald A. Crosby, Nature as Sacred Ground: A Metaphysics for Religious Naturalism (New York: State University of New York Press, 2015).

2 Donald A. Crosby, "Probabilism, Emergentism, and Pluralism: A Naturalistic Metaphysics of Radical Materialism," American Journal of Theology and Philosophy 37, no. 3 (2016): 217-227.

3 Ibid., 217-218.
} 
the emergent product of natura naturans; the creative processes of the natural order and the causal interplay of wholly material constituents.

In Thomas Nagel's Mind and Cosmos we find a similar emphasis on the explanatory relevance of teleology for making sense of human mentality. However, contrary to Crosby's radical materialism, Nagel's ontology is thoroughly non-emergentist and significantly closer to neutral monism and panpsychism. ${ }^{4}$ Teleology is not a second-order property (ontologically derivable from lower properties), but is taken as fundamental by Nagel. In order to explain higher features of reality - such as consciousness, cognition, and values - we need to posit teleological principles. Nagel's controversial metaphysical contribution amounts, according to Crosby, to a problematic "panteleology" that relies too much on the limits of the natural sciences. Although they both base their projects on epistemic pluralism, and they both critique causal reductionism, Crosby and Nagel seek to ground teleology within the natural in markedly different ways.

Crosby's and Nagel's metaphysical projects share many points of agreement. They both claim to be naturalistic. Crosby and Nagel are equally critical of ontological reductionism. Moreover, they both recognize the need for a genuine teleology. Yet, they disagree significantly concerning the nature and potentialities of matter and the proper explanatory route towards teleology. For Nagel, materialism is the sworn enemy to consciousness and meaning, so he seeks to base evolution on a panpsychist ontology that would allow for an intrinsic teleology. Crosby's ambition, on the other hand, is to formulate an expansive and more "radical" materialism that is friendly to teleology, consciousness, and other higher-level phenomena.

This article will explore this disagreement further. I will argue that Crosby's emergentist account of teleology faces significant challenges. Moreover, I will argue that Crosby, in the

\footnotetext{
${ }^{4}$ Thomas Nagel, Mind and Cosmos: Why the Materialist Neo-Darwinian Conception of Nature is Almost Certainly False (Oxford and New York: Oxford University Press, 2012), 56-58.
} 
spirit of anti-reductionism, ought to take Nagel's fundamental teleology seriously due to its epistemic benefits.

\section{Fundamental Teleology}

In a similar vein to Crosby, Nagel considers the development of an adequate form of naturalism to be directly relevant for human meaning and purpose. Naturalism needs to be dislodged from hardheaded atheism. The ongoing project of developing a naturalistic account of the universe is not merely an intellectual exercise, but it carries important implications for "the cosmic question" regarding human existence and "the relation of individual human life to the universe as a whole." ${ }^{5}$ On a stricter form of naturalism, the scientific worldview abolishes all forms of cosmic meaning. Nagel, therefore, seeks to take naturalism beyond this meaning-negating account of evolutionary naturalism, towards an enriched understanding of both humanity and the natural. Such re-enchantment of the natural will involve a reappreciation of teleology within the cosmos. Nagel writes, "As it is usually understood, evolutionary naturalism is radically antiteleological. This implies that it is not suited to supply any kind of sense to our existence, if it is taken on as the larger perspective from which life is lived." ${ }^{\prime 6}$ Because evolutionary naturalism reduces life to an accidental consequence of biology, chemistry, and physics, it also makes human life meaningless.

In Mind and Cosmos, Nagel launches a case against "psychophysical reductionism” (and follows up his critique of physicalism made in earlier writings). The logic of psychophysical reductionism can be summarized in this way: given that our mental capacities depend on a biological substrate, the constituents of that biological substrate must be sufficient to explain the appearance and nature of our mental capacities. Thus, the thesis of psychophysical

\footnotetext{
${ }^{5}$ Thomas Nagel, Secular Philosophy and the Religious Temperament: Essays 2002-2008 (New York and Oxford: Oxford University Press), 5.

${ }^{6}$ Ibid., 15.
} 
reductionism, which is a reconstructive explanatory strategy, states that an explanation of a higher-level phenomenon is possible by showing how the combination of lower-level properties yield the kind of phenomena that we find at the higher levels of reality. Nagel, therefore, argues that this form of reductionism proceeds on the assumption that "everything in the world is physical and... everything that happens in the world has its most basic explanation, whether we can come to know it or not, in physical law, as applied to physical things and events and their constituents." For Nagel, as we can see, materialism is intrinsically linked up with an unacceptable reductionism that renders higher-level phenomena unintelligible.

In continuation with his previous arguments against physicalist endeavors, Nagel argues that reductive explanatory commitments (i.e. commitments to the primacy of mechanism) come up short against the irreducible character of subjective experiences. ${ }^{8}$ The mere assertion of potential underlying causes for the existence of eyes, ears, central nervous systems, etc. is not enough to provide an explanation for the emergence of human subjectivity. Thus, physicalism is "incomplete even as a theory of the physical world, since the physical world includes conscious organisms among its most striking occupants." ${ }^{" 9}$ A reductive programme is committed to causal explanations, but such explanations are deficient for explaining the emergence of consciousness.

Values, according to Nagel, are utterly mysterious phenomena within the framework of materialism. As he says, real "value - good and bad, right and wrong - is another of those things, like consciousness and cognition, that seem at first sight incompatible with evolutionary naturalism in its familiar materialist form.." ${ }^{10}$ Nagel takes a realist stand

\footnotetext{
${ }^{7}$ We find this view in the physicalist/naturalist programs of Frank Jackson and David Papineau. See Frank Jackson, From Metaphysics to Ethics: A Defence of Conceptual Analysis (New York and Oxford: Oxford University Press, 1998); David Papineau, Philosophical Naturalism (Oxford: Blackwell, 1993).

${ }^{8}$ Nagel, Mind and Cosmos, 44.

${ }^{9}$ Ibid., 45.

10 lbid., 97.
} 
regarding the reality of values as he seeks to steer a path between heavy metaphysics and subjectivism. In contrast to subjectivism, Nagel denies that values depend on, or can be reduced to, motivational dispositions and responses. ${ }^{11}$ Rather, value judgements are correct insofar as they are "in accord with the actual structure and weight of values in the case at hand." 12 How, then, does Nagel go about justifying his own preferred value realism? Nagel concedes that the debate between value-subjectivists, reductionists, and realists, cannot be settled in terms of metaphysical arguments, nor by appealing to the success of science. Real support for "realism can come only from the fruitfulness of evaluative and moral thought in producing results, including corrections of beliefs formerly widely held and the development of new and improved methods and arguments over time."13 Thus, Nagel's defense of value realism is pragmatically pursued, compared to his metaphysical defense of the irreducibility of subjective experiencing.

Such pragmatic considerations become evident in Nagel's analysis of Sharon Street's paper on the status of value realism in light of evolutionary naturalism. A naturalistic understanding of the processes and directionality of evolution, argues Street, precludes the existence of ontologically odd moral properties. Given, however, that the evidence for Darwinian evolution is strong, moral realism must be abandoned. ${ }^{14}$ Nagel is in agreement with Street; if we approach moral values from a Darwinian (naturalistically construed) perspective then such "extra-natural" properties should be discarded. The main problem with this line of reasoning, Nagel argues, is that it goes contrary to "the immediate conviction that objectivity is not an illusion with respect to basic judgements of value" - which an eliminativist dismissal of values would have us think. ${ }^{15}$ While values such as pleasure and

\footnotetext{
11 lbid., 98.

12 Ibid., 100.

13 Ibid., 104.

${ }^{14}$ Ibid., 105. See Sharon Street, "A Darwinian Dilemma for Realist Theories of Values," Philosophical Studies 127, no. 1 (2006): 109-166.

${ }^{15}$ Nagel, Mind and Cosmos, 110.
} 
pain can be explained (to some degree) "by natural selection, their objective value, our capacity to recognize it..." cannot be sufficiently explained in terms of natural categories.

So far, Nagel's conclusion regarding the philosophical adequacy of materialism is largely negative. However, even if materialism proves unsustainable, "we need some idea of what might replace it." ${ }^{\prime 16}$ Materialism lacks the adequate ontological resources for accounting for higher-level facts, including consciousness and values. To make such facts intelligible, "a postmaterialist theory would have to offer a unified explanation of how the physical and the mental characteristics of organisms developed together..." ${ }^{17}$ Mere modification of materialism will not be sufficient - nor can a materialist explanation of the behavior of organisms be considered explanatorily sufficient.

Nagel concludes that a purely causal account (based on either reductive or emergent frameworks) cannot answer the fundamental question regarding human mentality; that is, "why it was likely that organisms of the kind that have consciousness would arise." 18

Nagel, in departing from the logic of purely causal explanations, ventures instead into the domain of teleology. This strategy, Nagel confesses, is a throwback to an Aristotelian conception of the natural order. On such a view, there are "natural teleological laws governing the development of organization over time, in addition to laws of the familiar kind [efficient causation] governing the behaviour of the elements." ${ }^{19}$ Moreover, such laws must be genuinely universal, and not be thought of as "just the description of a single goal-seeking process." 20 The hypothesis of natural teleology implies that "the natural world would have a propensity to give rise to beings of the kind that have a good - beings for which things can be

\footnotetext{
16 Ibid., 15.

17 Ibid., 46-47.

18 Ibid., 60.

19 lbid., 66.

${ }^{20}$ Ibid., 67. Nagel concedes that if a reductive causal alternative could be rendered intelligible, it would have

"have the attraction of greater unity than the teleological..." Ibid., 67.
} 
good or bad." ${ }^{21}$ However, given that such a teleological process accounts for the emergence of both good and evil, "it is not a candidate for a purely benign teleological explanation: a tendency toward the good."22

This proposal is consistent with a general form of monism concerning the ontological structure of nature, and it lends itself to panpsychism or some theory of protoconsciousness/proto-mentality according to which mind is a basic constituent of the physical. Nagel's universal monism stresses, therefore, the unbreakable connection between the mental and the physical. ${ }^{23}$

\section{Emergentist Teleology}

Crosby's radical monism is based on an emergentist understanding of the workings of nature, and such monism forms the basis for his teleological proposal. ${ }^{24}$ This emergentist framework is expressed by Crosby in the following way: "with higher levels of organization, new properties of matter come into being, and these new properties cannot be resolved into the traits of matter at lower or fundamentally different levels of organization." ${ }^{25}$ Here we can see how Crosby expresses two essential ingredients to any (strong) emergence theory: First, there is the commitment to the idea that emergent phenomena are irreducible with respect to their underlying material base structure. This idea is usually coupled with some notion of epistemic unpredictability, meaning that "Emergent properties are irreducible to, and

\footnotetext{
${ }^{21}$ Ibid., 121. Nagel's teleology is influenced by a paper written by John Hawthorne and Daniel Nolan: "What would teleological causation be?" in Metaphysical Essays, ed. John Hawthorne (Oxford: Oxford University Press, 2006), 265-283.

${ }^{22}$ Nagel, Mind and Cosmos, 122. Nagel acknowledges that nature is necessarily a mix of goods and evils. Crosby expresses something similar in Living with Ambiguity: Religious Naturalism and the Menace of Evil (New York: State University of New York Press, 2008).

${ }^{23}$ Ibid., 63.

${ }^{24}$ Crosby distinguishes his own radical monism from three other monistic understandings: monistic idealism, monistic materialism, and monistic panpsychism. Crosby, Nature as Sacred, 21, 29, 31, 32.

${ }^{25}$ Crosby, Nature as Sacred, 30.
} 
unpredictable from, the lower-level phenomena from which they emerge." ${ }^{26}$ On this reading of emergence, it is commonly maintained that the irreducibility of higher-level phenomena presupposes the idea that reality is hierarchically structured into distinct ontological levels.

Emergentists, therefore, deny that novel properties are "additive" or "subtractive". That is, such properties cannot be "mathematically calculated, or logically deduced, on the basis of the properties from which they emerge (so the whole is not a mere 'sum' of its parts)."27 However, supervenience and irreducibility/unpredictability are not sufficient for framing an ontologically robust conception of the emergent order. $^{28}$ Something else is needed (given that epistemic emergence is logically compatible with ontological reductionism).

This leads to the second feature of emergence theory, novelty, which is a key term in emergentist discourses. Roughly speaking, someone who holds to this idea would say that $E$ is genuinely new and novel if the properties of $E$ are not present in the subvenient structure of $E$. Historical figures in the emergence debate, such as Samuel Alexander, have insisted that emergent phenomena must bring with them something ontological if they are to avoid the epiphenomenalist threat. More specifically, emergentists argue for the causal efficacy of higher-level properties. That is, E's behavior is not determined by upward causation. Rather, $E$ exerts irreducible downward causal influence on its subvenient level; i.e., "some whole has an active non-additive causal influence on its parts. ${ }^{29}$

\footnotetext{
${ }^{26}$ Philip Clayton, "Conceptual Foundations of Emergence Theory," in The Re-Emergence of Emergence: The Emergentist Hypothesis from Science to Religion, eds. Philip Clayton and Paul Davies (Oxford and New York: Oxford University Press, 2008), 2.

27 Jaegwon Kim, “Emergence: Core Ideas and Issues," Synthese 151, no. 3 (2006): 551.

${ }^{28}$ I follow Kim in defining supervenience in terms of a relationship of dependency between higher-level and lower-level facts. He writes, "things are connected with one another in that whether something exists, or what properties it has, is dependent on, or determined by, what other things exist and what kinds of things they are." Jaegwon Kim, Supervenience and Mind: Selected Philosophical Essays (Cambridge and New York: Cambridge University Press, 1993), 53. The logic of supervenience is frequently applied on the body-mind problem, which means that "All psychological states and processes supervene on the contemporaneous physical states of the organism." Jaegwon Kim, "Psychophysical Supervenience," Philosophical Studies 41, no. 1 (1982): 53.

${ }^{29}$ Philip Clayton, Mind and Emergence: From Quantum to Consciousness (Oxford and New York: Oxford University Press, 2004), 49. It is possible to distinguish between a weaker and stronger version of downward causation. On the weaker version, "the causal impact of the high-level phenomenon is deducible in principle,
} 
Crosby argues in line with classical emergentism that the question of ontological novelty is intimately connected with issues of causality. If novelty entails "something different" then we need a better understanding of the cause-effect relation. For Crosby, the phenomenon of novelty "is not completely contained in the causal past but is added to it." 30 Nature is not passive but active. Complex combinations "of continuity and novelty [the interplay between upward- and downward causation] are taking place all around it, even if only in relatively imperceptible or unnoticeable degrees, and these combinations are exerting mutual effects on one another." ${ }^{31}$ Indeed, without this novelty the flow of time and the very existence of time would be ontologically impossible. ${ }^{32}$

Thus, if teleology is real then it must be construed as an emergent phenomenon in terms of the configuration of material constituents. That is, "it is a function of complexity of material organization and becomes both possible and actual only when sufficient complexity has been realized through long-term evolutionary changes." ${ }^{33}$ Teleology, which is truly emergent, cannot be reduced to "efficient causality or to linear causal developments."

Crosby rejects Nagel's primordial teleology, which is also expressed within Whitehead's process metaphysics. For Crosby, novelty is a primordial phenomenon, but teleology is not. Indeed, it is this primordial novelty in combination with the necessary causal continuity that allows for the emergence of higher-level teleology and, consequently, the emergence of mind and human freedom. Thus, teleology is derivate from material organization, and not a

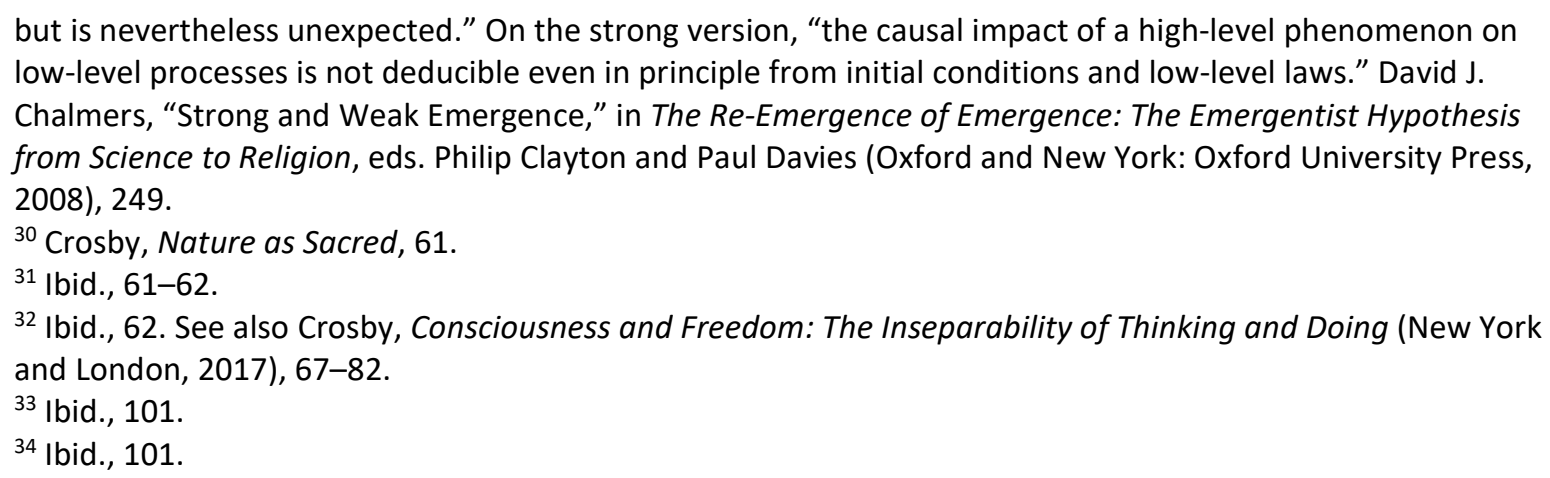
low-level processes is not deducible even in principle from initial conditions and low-level laws." David J. Chalmers, "Strong and Weak Emergence," in The Re-Emergence of Emergence: The Emergentist Hypothesis from Science to Religion, eds. Philip Clayton and Paul Davies (Oxford and New York: Oxford University Press, 2008), 249.

${ }^{30}$ Crosby, Nature as Sacred, 61.

31 Ibid., 61-62.

32 Ibid., 62. See also Crosby, Consciousness and Freedom: The Inseparability of Thinking and Doing (New York and London, 2017), 67-82.

33 Ibid., 101.

${ }^{34}$ Ibid., 101. 
fundamental aspect of the physical. As Crosby says, "I restrict teleological action or behavior to emergent conscious beings, and nature is not a conscious being." 35

\section{Critiquing Emergent Teleology}

In this section I want to call into question an emergentist conception of teleology. While I admire Crosby's ambition to defend teleological realism, his chosen framework seems insufficient for the task at hand. I argue that emergent teleology faces four different, but connected, metaphysical problems: The Placement Problem, the Origination Problem, The Materialist Compatibility Problem, and the Epiphenomenalist Problem. The failure to address these problems results in an impoverished conception of teleology, which threatens the overall plausibility of Crosby's religion of nature.

What is the Placement Problem? A placement problem emerges when we try to place concepts that we use in everyday life and in numerous human practices in the world as described by contemporary science. Thus we ask, "If all reality is ultimately natural reality, how are we to 'place' moral facts, mathematical facts, meaning facts, and so on?"36 People speak in certain ways and employ a variety of high-level concepts. A naturalist, therefore, wants to understand how those ways of speaking and those kinds of concepts can also be the kind of things studied by science. For example, how can a normative concept also be a natural fact? This is a metaphysical game of matching a true statement with natural facts, and naturalists have come to explore a variety of strategies for successfully engaging in this philosophical game. ${ }^{37}$ Crosby's metaphysical proposal amounts to an emergentist matching strategy, whereby a higher-level fact depends on a natural fact while nevertheless being

\footnotetext{
35 Donald A. Crosby, Novelty (New York and London: Lexington Books, 2005), 52.

${ }^{36}$ Huw Price, Naturalism without Mirrors (Oxford and New York: Oxford University Press, 2011), 187.

${ }^{37}$ Price, 185-187. Price argues that this problem emerges as a result of the metaphysical commitments of "object naturalism", according to which there is nothing but the natural world. Thus, all objects and facts must be natural facts. The problem for this type of naturalism is to demonstrate how the richness of human linguistic practices can be metaphysically matched to natural/physical facts.
} 
irreducible to it. Crosby's emergentism implies a clear rejection of "identitism" - the idea that higher-level properties are identical to physical properties. However, as Terry Horgan and Mark Timmons ask, "If there are such FACTS and PROPERTIES but they are not identical to naturalistic ones, can their existence really be made to square with metaphysical naturalism?"38 Crosby's emergentism is reductive in a particular sense, even if it is not committed to a "type-type inter-level connections that make for inter-theoretic reduction in science." ${ }^{39}$ Still, the emergentist goal - if it is to be regarded as a member of the naturalistic family - is to "give a tractable specification" in non-teleological terms of the sufficient conditions for the physical instantiation of teleological properties. ${ }^{40}$

However, such tractable specification does not seem possible given an emergentist strategy and its commitment to the philosophical claim that emergent phenomena are unpredictable. Proponents of emergence theory emphasize the unpredictability of higher-level phenomena in order to safeguard the irreducibility and reality of such phenomena. If they were predictable, then it would be possible to reduce their ontological structure and causal capacities to their underlying base structure. Although this resistance to reductionism is understandable, it makes higher-level phenomena, such as teleological properties, sui generis and unexplainable. If teleological properties are truly sui generis with regard to their underlying natural/physical base, then a significant issue emerges: How can the emergentist coherently claim that teleological properties are purely natural when it is not possible to provide tractable specifications for the emergence of such properties $?^{41}$ The unpredictability

\footnotetext{
${ }^{38}$ Terry Horgan and Mark Timmons, "Metaphysical Naturalism, Semantic Normativity, and Meta-Semantic Irrealism," Philosophical Studies 4, no. 1 (1993): 180-204.

${ }^{39}$ Terence Horgan, "From Supervenience to Superdupervenience: Meeting the Demands of a Material World," Mind 102, no. 408 (1993): 579.

${ }^{40}$ Ibid.

${ }^{41}$ I have described this as the "Problem of Competing Ontologies". That is, the sui generis character of higherlevel properties supports a variety of ontologies, including non-naturalistic ones. In order to avoid the problem of competing ontologies, the naturalist has to demonstrate that higher-level properties are purely natural. See Mikael Leidenhag, "From the Limits of Science to the Limits of Metaphysics: A Philosophical
} 
thesis of emergence, while it provides support for non-reductionism, undercuts and destabilizes emergence theory as an ontological project. Indeed, it leads to a severe placement problem.

The second problem concerns naturalistic property dualism as a whole. If we adopt a purely naturalistic conception of the progress and directionality of evolution, then how is it possible - as it is claimed on a naturalistic story - for natural selection to produce nonphysical/extra-natural properties ${ }^{42}$ What would be the adaptive value of non-physical properties? ${ }^{43}$ Once again, given the unpredictability thesis, emergentists have no way of spelling out the ontological conditions for the instantiation of teleological properties. Indeed, emergence theory seems to entail metaphysical quietism regarding the nature of higher-level properties. It remains to be seen if emergence theory can address the Origination Problem of teleological properties.

Crosby is clear that he adopts a materialist outlook on nature; "for me all existence is material or a form or function of matter, there is no contrast to materiality as far as actual existence is concerned." ${ }^{44}$ His version of emergentism, therefore, is nonreductive and physicalist, which requires a change in understanding of the concept of matter. ${ }^{45}$ Crosby’s emergentism implies the metaphysical claim that all substances are material substances, and that teleological properties are ontologically distinct from material properties. I will argue that these two commitments do not mesh well together, but give rise to the Materialist Compatibility Problem.

Evaluation of Fiona Ellis's Naturalistic Theology," in Are There Limits to Science? ed. Gillian Straine (Newcastleupon-Tyne: Cambridge Scholars Publishing, 2017), 21-39.

42 William G. Lycan, "Is property dualism better off than substance dualism?" Philosophical Studies 164, no. 2 (2013): 537.

${ }^{43}$ I am following Lycan in construing property dualism as the thesis that there are both physical and nonphysical properties, i.e. properties that are ontologically non-construable in terms of physical properties, laws, and processes.

${ }^{44}$ Crosby, Nature as Sacred, 32.

45 Ibid., 29. 
Susan Schneider has explored this materialist tension. ${ }^{46}$ Let us assume the bundle theory of substances, which holds that substances are constituted by the properties that they possess. The properties in this case are higher-level properties in general: intentional/teleological properties, phenomenological properties, qualia, and so on. But, if we assume that physical substances are constituted by such high-level properties, as it is claimed on this property dualist picture, then why should we assume that the substance is physical? As Schneider asks, "Why is the mind not, instead, a 'hybrid' substance - one which consists in both physical and qualitative properties?" ${ }^{47}$ Indeed, if we consider the phenomenon of human mentality, such a position would pull us in the direction of William Hasker's emergent dualism. ${ }^{48}$ Hasker's non-Cartesian dualism starts off with property dualism, but goes on to demonstrate that such dualism alone is not sufficient for accounting for human consciousness; "what is needed is an emergent individual, a new individual entity which comes into existence as a result of a certain functional configuration of the material constituents of the brain and the nervous system." ${ }^{49}$ Of course, this move towards emergent dualism would mean abandoning Crosby's materialism. What the emergent materialist needs to do in order to retain a commitment to substance materialism is to "explain why the presence of irreducible qualia is compatible with the mind's being a physical substance..."50

Lastly, emergent materialism seems unable to provide teleological properties with the proper causal potency that is required of truly emergent phenomena. Jaegwon Kim has highlighted several causal problems in the emergentist understanding of consciousness, and higher-level phenomena in general. ${ }^{51}$ The problem is that if an emergent property $E$ emerges

\footnotetext{
${ }^{46}$ Susan Schneider, "Why property dualists must reject substance physicalism," Philosophical Studies 157, no. 1 (2012): 61-76.

47 Ibid., 65.

${ }^{48}$ Schneider discusses E.J. Lowe's Non-Cartesian substance dualism as a closely related position. Schneider, 66.

${ }^{49}$ William Hasker, The Emergent Self (Ithaca: Cornell University Press, 1999), 190.

50 Schneider, 65.

51 See especially Jaegwon Kim, “Emergence: Core Ideas and Issues," Synthese 151, no. 3 (2006), 547-559. Scot

D. Yoder relies on Kim's arguments when he explicates the central problems for those religious naturalists who
} 
from a material level $M$, and the causal capacities of $E$ are ontologically dependent on $M$, then is seems as if $M$ does all the causal work. That is, $E$ seems to be ontologically redundant given that the causal contributions of $E$ are already contained at the base level. Thus, as Kim argues, if the emergentist wants to retain $E$ then she needs to provide some additional arguments for thinking that $E$ enjoys novel, irreducible causal capacities; capacities that depend on but go beyond the purely material. If left unaddressed, an emergentist view of causal powers might pave the way for epiphenomenalism.

In light of the problems of an emergentist teleology, we should probe deeper into some of the benefits of adopting Nagel's teleological framework. Indeed, those like Crosby who take teleology and human freedom seriously should consider the epistemic benefits of fundamental teleology.

\section{Epistemic Benefits of Fundamental Teleology}

We need to retrieve a realist and non-reductive conception of teleology in order to make sense of human reasoning and freedom. This point is shared by Crosby and Nagel. However, Crosby's emergentist take on teleology pictures it as ontologically derivative. That is, as a secondary property that is ontologically dependent on less complex phenomena. His emergentism is still too committed to the logic of reductionism, and this creates severe problems for the emergentist and religious naturalist who seek to uphold causal realism when it comes to teleological properties and, thus, human creatures. My advice is to pursue Nagel's fundamental teleology. Nagel confesses that his proposal is speculative and underdeveloped. I shall try to unpack some of the claims associated with fundamental teleology, which will allow us to extract some further benefits of adopting a Nagel-type teleology.

base their religious vision on contemporary emergence theory. See, Scot D. Yoder, "Emergence and Religious Naturalism: The Promise and Peril," American Journal of Theology and Philosophy 35, no. 2 (2014): 163-164. Yoder further notes that Kim's challenge to strong emergence and downward causation have not been addressed by religious naturalists. 
If teleology is truly fundamental, as is suggested on Nagel's account, then we should expect it to be present in both living and non-living systems. David Oderberg provides a sophisticated argument for the possibility of attributing teleological qualities to the non-living world. It is easy to imagine teleology and teleological behavior in the living world. In living organisms, we can understand teleology as "the natural capacity of an object for selfperfective immanent activity. Living things act for themselves in order to perfect themselves..."52 By "perfecting" Oderberg means "that an entity acts so as to produce, conserve and repair its proper functioning as the kind of thing it is - not to reach a state of absolute perfection..." ${ }^{53}$ Living entities exercise immanent causation, a form of "causation that begins with the agent and terminates in the agent for the sake of the agent."

Can we apply this form of teleology to the inorganic world and non-living phenomena? Is this an appropriate strategy for explicating Nagel's teleology? No, because inorganic entities do not engage in self-perfecting activity. Indeed, no inorganic entity has intrinsic telos, such that the entity behaves in a way so as to achieve some natural fulfilment. ${ }^{55}$ However, if we exclude immanent causation and intrinsic telos from the picture, then is it even metaphysically interesting, philosophically coherent, and semantically meaningful to talk about inorganic teleology? If Nagel's teleology amounts to an ontologically confused language-game, then it would not fare much better than the emergentist teleological strategy.

Oderberg proposes that we think of inorganic teleology in terms of the part, role, or function that inorganic phenomena play in the preservation of other entities. Oderberg appeals to two natural processes or inorganic cycles: 1) Rock cycles - the transitional process

\footnotetext{
52 David S. Oderberg, "Teleology: Organic and Inorganic," in Contemporary Perspectives on Natural Law: Natural Law as a Limiting Concept, ed. A.M. González (New York and London: Routledge, 2008), 261. Oderberg believes that we can understand organic teleology in terms of final causation, but he prefers the term "immanent causation". 
between sedimentary, metamorphic and igneous rocks. 2) Water cycles - the transitional process of water changing between solid state (ice), liquid state (water), and gas state (water vapor). Why should one think of these natural processes as teleological? One could appeal to their order and complexity to ground teleological vocabulary, but Oderberg argues that such phenomena, albeit significant, are not sufficient to invoke teleological language. ${ }^{56}$ Rather, Oderberg seeks to bridge function-talk with teleology-talk by bringing out the functional character of rock cycles and water cycles. Each transitional state of the rock and water cycle play a functional role in bringing about another state within the cycle.

As Oderberg points out, this is a natural part of the geologist vocabulary: "“How does the evaporation function in the water cycle?' 'It does such-and-such.' 'What role does sedimentation play in the rock cycle?' 'It functions in such-and-such way." 57 Thus, given that function-talk is a form of teleological talk, we can locate teleology in the inorganic world.

Of course, the skeptic who believes in teleology only in the organic world, ${ }^{58}$ or the person who rejects teleology altogether, might say that Oderberg's proposal rests on a problematic conflation between teleology-talk and ordinary non-teleological causation. If this were the case, however, then it would be impossible to pick out relevant causal relations among the total set of causal relations. As Oderberg writes,

"Suppose that, in some place, sedimentation blocks the water supply to a region. Or suppose, somewhat more fancifully, that the presence of magma causes some species of bird to migrate. Neither of these phenomena are part of the rock cycle. They might be of interest to scientists who study water supplies in a region or bird migration, but if you want to know about the rock cycle you do not need to know about the water supply or bird migration." 59

\footnotetext{
56 Oderberg, 267-268.

57 Oderberg, 269.

${ }^{58}$ For a purely organic teleology, see Denis M. Walsh, Organisms, Agency and Evolution (Cambridge: Cambridge University Press, 2015).

59 Oderberg, 273-274.
} 
Once again, given that it is possible to single out particular causal relations regarding the rock cycle, it seems that such teleological ascriptions cannot be reduced to mere efficient causality. We can appreciate this point even more if we compare the rock and water cycle with other inorganic processes and events. Oderberg asks us to consider a stick that floats downstream, gets stuck and creates a backwash that keeps the stick pinned to the rock. ${ }^{60} \mathrm{In}$ some very loose sense, given the order that the stick and the backwash display, we might be able to view this as a physical system - as in "the presence of a number of interrelated elements working together to produce a unified whole." ${ }^{61}$ However, there is no "genuine roleplaying" in this scenario. There is no contribution of a function to anything else, and nothing seems to go beyond mere efficient causality. Indeed, this is most likely why, as Oderberg further notes, we find plenty of scholarly investigations pertaining to rock cycles and water cycles, but no "one writes books about sticks pinned against rocks." 62 The rock and water cycles can be considered systems, which make them fit for serious investigation.

Another objection could be that Oderberg's proposal is no more than useful fiction. The skeptic might say: "Sure, if one stipulates some thin non-organic notion of teleology it becomes easier to explain teleology at the organic level. But, this is not to say that there actually is such a thing as non-organic teleology in the natural order. This is just to confuse epistemic benefits of non-organic teleology with ontology." However, once again, if the skeptic is correct in her assertion that this is just useful fiction, then it would be impossible to pick out the relevant causal factors. Perhaps "the reason such teleological talk is both useful and common is that it represents something true." ${ }^{63}$ Likewise, the reason that we can differentiate relevant causal factors from those that are non-relevant speaks in favor of an ontological conception of non-organic teleology.

\footnotetext{
60 Oderberg, 268. This scenario is also discussed in Mark Bedau, "Can Biological Teleology be Naturalized?" The Journal of Philosophy 88, no. 11 (1991): 647-655.

61 Ibid.

62 Oderberg, 271.

63 Oderberg, 275.
} 
To conclude this section. Oderberg's proposal provides an interesting way to metaphysically explicate the idea of fundamental teleology. A fundamental teleology, offered by Nagel and further explicated by Oderberg, would allow us to ontologically ground stronger forms of teleology without collapsing higher-level teleology to lower-level teleology. This speaks strongly in favor of Nagel's post-materialist ambition of placing teleology at the fundamental strata of physical reality.

Moreover, it does not end up with the emergentist problem of positing an ontological gap between higher forms of teleology and the physical level that we are epistemically suspended from addressing. The idea of fundamental teleology is by many considered bizarre. But why should we think that? Indeed, "Why should we not expect a kind of graduation in nature, from a thin, attenuated kind of functionality in the inorganic world to a full, rich kind of purposive behaviour such as we find in the living world?"64 Nagel's fundamental teleology can help to make sense of higher-level phenomena and the richness of physical reality.

\section{Concluding Remarks}

I have recommended for teleological realists to take the theory of fundamental teleology seriously. Crosby recognizes the value of teleology for religious naturalism, but his preferred emergentist ontology seems to leave teleology brute and unexplainable. Indeed, emergence theory seems to encounter severe metaphysical problems which, in turn, undermines the plausibility of religious naturalism. Due to the epistemic benefits of fundamental teleology as shown through Oderberg's proposal - Nagel's postmaterialist theory deserves careful consideration. ${ }^{65}$

\footnotetext{
${ }^{64}$ Oderberg, 278.

65 I would like to thank two anonymous reviewers for their helpful suggestions and comments.
} 